\title{
Predictors of cigarette and shisha use in Nima and Osu communities, Accra, Ghana: A cross-sectional study
}

Labram M. Massawudu'1,2, Divine D. Logo ${ }^{3}$, Felix B. Oppong ${ }^{4}$, Samuel Afari-Asiedu ${ }^{5}$, Zuliehatu Nakobu6, Leonard Baatiema John K. Boateng ${ }^{8}$

\begin{abstract}
INTRODUCTION Tobacco use in any form leads to mortality and morbidity of millions of people every year, not only tobacco users but also non-users by inhaling secondhand tobacco smoke. The objective of this study was to assess predictors of cigarette and shisha use in urban and urban slum communities in Accra, Ghana.
\end{abstract}

METHODS A cross-sectional study design was employed, using a quantitative data collection technique over two months, May to June 2017. Logistic regression was used to study the association between demographic characteristics of respondents and cigarette/shisha use, and data were analyzed in STATA.

RESULTS The study included 389 respondents from urban (135) and urban slum (254) communities in the capital Accra. The prevalence of ever smoking cigarettes, shisha and electronic cigarettes was 24.9\% (95\% Cl: 20.8-29.5), 34.6\% (95\% Cl: 30.0-39.6) and 15.1\% (95\% Cl: 11.3-19.8), respectively. For current smokers, $13.1 \%$ (95\% Cl: 10.1-16.9) smoked cigarettes, $10.3 \%$ (95\% Cl: 7.6-13.7) smoked shisha, and 19.5\% (95\% Cl: 15.9-23.8) smoked either cigarettes or shisha. Respondents aged 26-35 years (OR=2.22; 95\% $\mathrm{Cl}$ : 1.08-4.56, $\mathrm{p}=0.029)$ and those with no employment $(\mathrm{OR}=2.30 ; 95 \% \mathrm{Cl}$ : 1.19-4.44, $p=0.013$ ) had higher odds of cigarette/shisha use compared to those aged 18-25 years and the employed, respectively.

CONCLUSIONS The provision of adequate resources and continued engagement of relevant stakeholders, can strengthen smoke-free law implementation in Ghana and protect citizens from the harmful effects of tobacco use.

\begin{abstract}
AFFILIATION
1 Vision for Alternative Development (VALD), Accra, Ghana

2 Department of Adult Education and Human Resources Studies, Wisconsin International University College,Accra, Ghana

3 Research and Development Division, Ghana Health Service, Ministry of Health, Accra, Ghana 4 Global Statistical Institute, Techiman, Ghana 5 Kintampo Health Research Centre, Ghana Health Service, Ministry of Health, Kintampo, Ghana

6 Animal Biology and Conservation Science Department, University of Ghana, Accra, Ghana 7 Noguchi Memorial Institute for Medical Research, University of Ghana, Accra, Ghana 8 School of Continuing and Distance Education, University of Ghana Learning Centres, University of Ghana, Accra, Ghana
\end{abstract}

\section{CORRESPONDENCE TO}

Divine D. Logo. Research and Development Division, Ghana Health Service, Ministry of Health, P.O. Box MB 190, Ministries, Accra, Ghana. Email: divine.logo@ghsmail.org ORCID ID:https://orcid.org/0000-0001-7742-933X

\section{KEYWORDS}

smoke-free, slum, shisha, Ghana, effective implementation, urban

Received: 23 August 2021

Revised: 6 October 2021

Accepted: 20 October 2021

\section{INTRODUCTION}

Tobacco remains the single most preventable risk factor that acts against present and future generations, having devastating health, social, environmental and economic consequences through its consumption and exposure ${ }^{1}$. It is one of the main public health problems killing over 8 million people, with 9 in 10 as a result of direct tobacco use, and 1 in 10 due to exposure to tobacco smoke ${ }^{2}$. It is a challenge to public health as 8 in 10 of 1.3 billion adult smokers are located in low- and middle-income countries including Ghana. This high level of tobacco consumption and exposure leads to high tobacco-related morbidity and mortality as a result of high level tobacco addiction ${ }^{3}$ and poverty within the immediate families of the tobacco users due to the diversion of household money from buying basic needs, such as food and shelter, to tobacco purchases ${ }^{4}$. Tobacco addiction and continuous use also lead to increased healthcare costs as a result of increased tobacco-related disease ${ }^{5}$. It is well documented that tobacco and tobacco products have no safe level of exposure. Cigarettes are the most commonly used $^{6}$ tobacco product followed by other types such as waterpipe tobacco (shisha), smokeless tobacco products, cigars, cigarillos, roll-your-own tobacco, pipe tobacco, bidis, and kreteks ${ }^{7}$. Waterpipe tobacco smoking (hookah, shisha, narghile) use is on the rise and has received attention from public health researchers and practitioners due to its fastgrowing use by and appeal to some populations ${ }^{8,9}$. This high demand for waterpipe (shisha) use, especially by youth can be attributed to the deceptive and aggressive marketing strategies of the tobacco industry, falsely presented as safer form of cigarette smoking ${ }^{6,9}$. Studies have confirmed that most shisha smokers are unaware of the harmful health 
effects of shisha smoking ${ }^{10,11}$ being deceived that the toxins in the smoke are filtered out by the water in the pipe ${ }^{12}$. Shisha contains the same chemicals and substances as cigarettes including carbon monoxide (CO), tar, nicotine and highly toxic and carcinogenic substances. Shisha has as well a higher level of heavy metals such as arsenic, nickel, cobalt, chromium, lead, and cadmium, than cigarette smoke ${ }^{13}$. As a result of the social interactions and long duration of shisha sessions, users and secondhand smokers are being exposed to greater levels of nicotine and $\mathrm{CO}$ than cigarette smoking and the amount inhaled can be more than ten times higher ${ }^{13}$.

The effects of tobacco use on the rather fragile economies of LMICs, including Ghana, may go unnoticed as a result of the paucity of data, yet tobacco use is significantly increasing healthcare costs from tobacco-related diseases and loss of human resources to morbidity and mortality ${ }^{14}$. Ghana is considered to be at the beginning of the tobacco epidemic compared to other African countries ${ }^{15}$. Despite the low prevalence of tobacco use, about 50 men and 16 women die every week as a result of tobacco-related diseases in Ghana. This constitutes $2.7 \%$ and $1.0 \%$ of the annual deaths among men and women, respectively ${ }^{16}$. The situation of the youth in Ghana is not so different from that of the adults, where the current report from the Global Youth Tobacco Survey (GYTS) shows that close to 9\% of the youth in Junior High Schools (JHS) aged 13-15 years are currently using tobacco products, and $1.3 \%$ are currently smoking shisha with the greater proportion among girls ${ }^{9,17}$. This study, therefore, assessed the predictors of tobacco use (cigarettes/shisha) in two communities in Accra, to provide data that will support the development of prevention strategies and policies for Ghana.

\section{METHODS}

\section{Study site}

The study was conducted in one urban slum (Nima) and one urban community (Osu) in the capital of Ghana, Accra. The Nima community is associated with slum settlement and lacks basic needs such as potable water supply, and faced with waste management issues. The community also has a high population of migrant workers from other regions of Ghana mostly from the three northern regions. The Nima community is among the areas known to indulge in the use of addictive substances including weeds, cannabis and tobacco, mostly among the youth as a result of high level of unemployment ${ }^{18}$. Osu on the other hand was a traditional coastal fishing settlement predominantly of the Ga ethnic group. However, it has grown into a network of cosmopolitan neighborhoods, with Oxford Street serving as the main center of the community. As a result of the variety of activities in the area such as cinemas, boutiques, cafes, restaurants, street food stalls, and art and craft stalls, it draws many people especially the youth and expatriates.

\section{Sample size calculation}

The study used the 2010 Ghana population census data ${ }^{19}$ to obtain the populations of households in the two communities, about 122000 and 184000 for Osu and Nima, respectively. By employing a random sampling technique, we used Slovin's formula to determine the sample size with a 5\% margin of error. The formula uses the study population $(\mathrm{N})$ and margin of error (e) to determine the sample size (n). A total of 389 respondents were required for the study. Of the 389 respondents, 135 (approximately $35 \%$ of the respondents) and 254 (approximately 65\% of the respondents) were selected from Osu and Nima communities, respectively. Study respondents were aged $\geq 18$ years.

Using the 2010 Population and Housing Census of Ghana ${ }^{19}$ as the sampling frame, 135 households were randomly selected from Osu and 254 from Nima. Only one respondent was interviewed in each household. Up to three repeat visits were made to households when no person aged $\geq 18$ years was present at the first visit. After three visits, a household was replaced with another randomly selected household within the sample frame. Also, nonresponding households were replaced with another randomly selected household within the respective sample frames. Subsequently, respondents from 389 households (135 from Osu and 254 from Nima) participated in the study.

Between May and June 2017, trained research assistants visited the selected households and explained the study and obtained informed consent through a signature or thumbprint, as appropriate. Respondents were assured of confidentiality of the information collected. Face-to-face interviews were performed using a structured questionnaire.

\section{Data collection}

A structured questionnaire ${ }^{20}$ was used to collect data from respondents in the two selected communities. Face-toface interviews were conducted, by the trained research assistants, among all respondents who consented to take part in the survey. Data on the use of cigarettes and other tobacco products, exposure to secondhand smoke, shisha smoking, electronic cigarette use, as well as demographic information of respondents were collected.

\section{Study measures}

\section{Cigarette smoking status}

We assessed the respondents' tobacco smoking status with two questions: "have you ever smoked a cigarette, even if it is one or two puffs?' and 'during the past 30 days, on how many days did you smoke cigarettes?'. Those who responded negatively to the two questions were classified as never smokers and former smokers, respectively. Both never and former smokers were categorized as current non-smokers.

\section{Tobacco smoking status}

We also assessed respondents smoking status with the question: "have you ever smoked tobacco products other than cigarettes, even if it is one or two puffs?'. Those who chose 
'yes' and 'no' were classified as ever tobacco smokers and never tobacco smokers, respectively.

\section{Willingness to quit smoking}

We assessed respondents' willingness to quit smoking by asking them three questions: 'do you want to stop smoking now?', 'do you ever try to stop smoking?' and 'do you think you could stop if you wanted to?' Those who responded 'yes' to all three questions were classified as willing to quit, those who responded 'no' or 'don't know' were classified as not willing to quit smoking.

\section{Exposure to secondhand smoke}

We also assessed respondents' exposure to secondhand smoke in their communities by asking them: 'do you think you are exposed to secondhand smoke?' and 'do you think the smoke from other people's tobacco smoking is harmful to you?'. Respondents who answered 'yes' showed an awareness of the harmful effects of tobacco use in their communities. Also, a further question included "how many days per week are you exposed to secondhand smoke in indoor or outdoor public places (public toilets, clubhouses, schools, shops, restaurants, shopping malls, movie theatres)?'.

\section{Shisha use status}

We also assessed shisha use among respondents in the community as follow:

'have you ever heard of shisha?', 'have you ever used shisha?', 'how often do you smoke shisha?', 'do you think the smoke from other people's shisha smoking is harmful to you?' and 'the last time you smoked shisha, where did you smoke it?'. Respondents who never heard of shisha were classified as non-shisha users, ones who heard and never used it before were classified as ever users, while respondents who used shisha during the last month before proceeding with the study were classified as current shisha users.

\section{Statistical analysis}

Frequencies and percentages were used to describe the distribution of the demographic characteristics of study respondents. The prevalence of ever and current use of cigarettes, shisha, and electronic cigarettes is presented with $95 \%$ confidence interval. We explored the difference in ever use of cigarettes, shisha, and electronic cigarettes, by sex and age. Chi-squared test was used to assess the association between the demographic characteristic of respondents and current cigarette and shisha smoking. Using a composite variable for current cigarette and/ or shisha smoking, logistic regression analysis was performed to assess the association between demographic characteristics of respondents and current cigarette/ shisha use. First, univariate logistic regression was used to assess the independent association of each of the demographic characteristics included in the study. Variables in the univariate analysis with $p<0.20$ were included in a multivariate logistic regression model. Also, given our interest in age and sex, these variables were included in the multivariate logistic regression model regardless of their statistical significance in the univariate analysis. A statistically significant level of $5 \%$ was used for the multivariate analysis. STATA version 14 was used for the statistical analysis.

Ethical approval for the study was obtained from the Ghana Health Service Ethics Review Committee (GHSERC017/08/17). Also, permission was sought from the Municipal Assembly before the conduct of the study. Consent was obtained from all participants after a detailed explanation of the study objectives, procedures, risks, and benefits have been provided in the presence of witnesses before any interview. Respondents were fully informed that their participation was voluntary and they could decide not to answer a question or withdraw from the study entirely, and data would be anonymously recorded.

\section{Table 1. Demographic characteristics of study respondents $(\mathrm{N}=389)$}

\begin{tabular}{|c|c|c|}
\hline Characteristics & $\mathbf{n}$ & $\%$ \\
\hline \multicolumn{3}{|l|}{ Residence } \\
\hline Urban & 135 & 34.7 \\
\hline Urban slum & 254 & 65.3 \\
\hline \multicolumn{3}{|l|}{ Sex } \\
\hline Male & 265 & 68.1 \\
\hline Female & 124 & 31.9 \\
\hline \multicolumn{3}{|l|}{ Age (years) } \\
\hline $18-25$ & 122 & 31.4 \\
\hline $26-35$ & 124 & 31.9 \\
\hline $36-45$ & 70 & 19.0 \\
\hline $46-70$ & 73 & 18.8 \\
\hline \multicolumn{3}{|l|}{ Marital status } \\
\hline Married/married before/co-habiting & 197 & 50.6 \\
\hline Single & 192 & 49.4 \\
\hline \multicolumn{3}{|l|}{ Education level } \\
\hline No, primary, JHS, middle & 180 & 46.3 \\
\hline Senior high school/vocational & 148 & 38.1 \\
\hline Tertiary & 55 & 14.1 \\
\hline Missing & 6 & 1.5 \\
\hline \multicolumn{3}{|l|}{ Employed } \\
\hline Yes & 315 & 80.9 \\
\hline No & 74 & 19.0 \\
\hline
\end{tabular}

JHS: junior high school. 
Figure 1. Sex (A) and age (B) distribution of ever users of cigarettes, shisha, and electronic cigarettes. The numbers above the bars are $p$-values for the test of differences in the prevalence
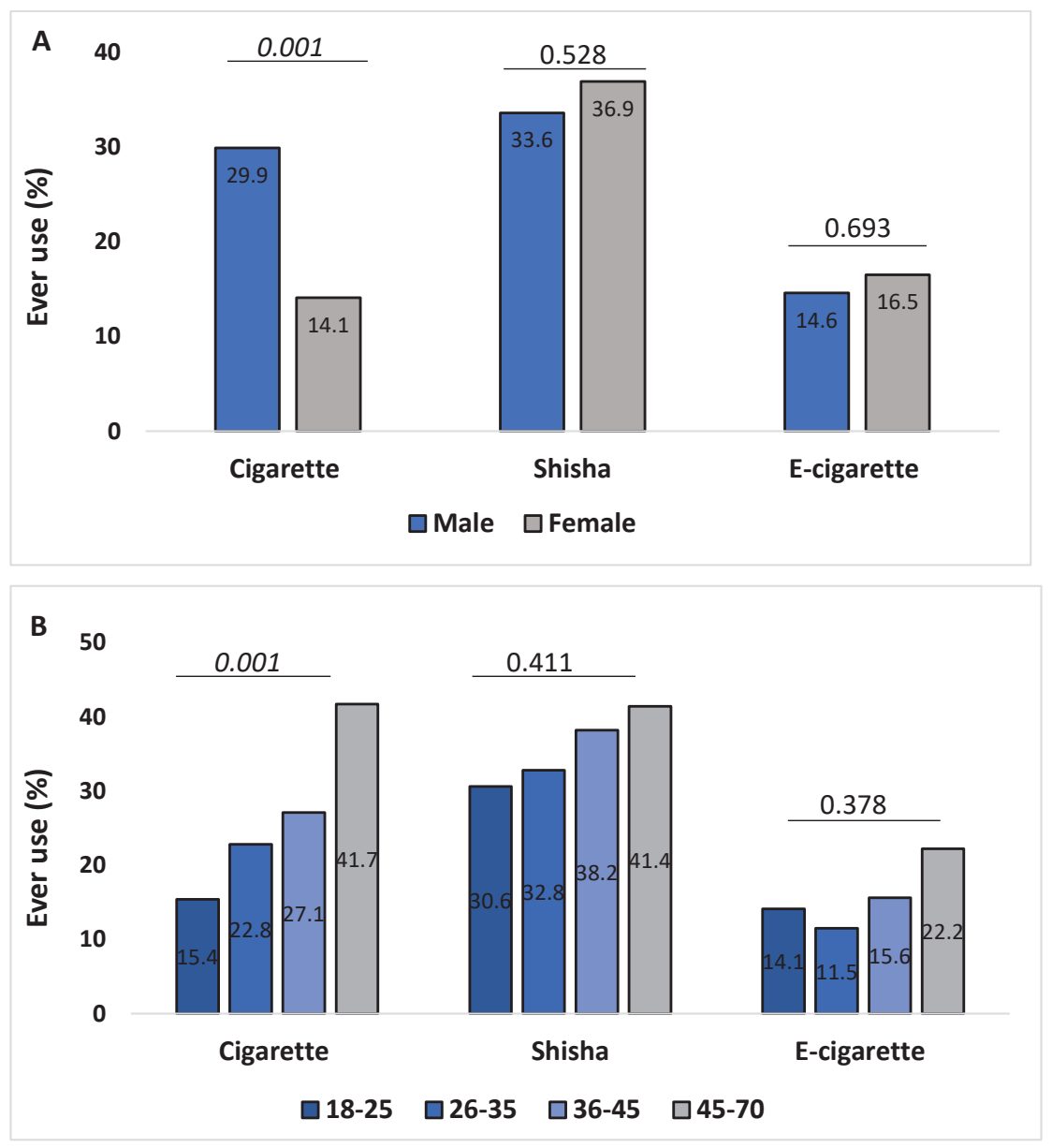

\section{RESULTS}

\section{Description of study participants}

Table 1 describes the demographic characteristics of the 389 respondents. There were more male participants than females, $68.1 \%$ versus $31.9 \%$. Most of the study respondents $246 / 389$ (63.3\%) were aged $<36$ years. Likewise, more than half of the respondents had education ranging from senior high school to tertiary education, and $19.0 \%$ of the respondents were unemployed.

Ever use of cigarettes, shisha, and e-cigarettes by sex and age

The prevalence of ever smoking cigarettes, shisha and electronic cigarettes was 24.9\% (95\% Cl: 20.8-29.5), $34.6 \%$ (95\% Cl: 30.0-39.6) and 15.1\% (95\% Cl: $11.3-$ 19.8), respectively. The distribution of ever-smokers of cigarettes, shisha, and electronic cigarettes by sex and age is shown in Figure 1. There was a significant difference in the proportion of respondents who have ever smoked cigarettes, by sex and age. Compared to females, more males have ever smoked cigarettes. Also, the percentage of respondents who have ever smoked cigarettes was higher among older participants.

Demographic characteristics of current cigarette or shisha users

The demographic characteristics of respondents by current cigarette and shisha use are presented in Table 2. The prevalence of current cigarette use was 13.1\% (95\% Cl: 10.1-16.9), current shisha use 10.3\% (95\% Cl: 7.6-13.7) and 19.5\% (95\% Cl: 15.9-23.8) smoked either cigarettes or shisha. Out of the demographic variables included in the analysis namely, place of residence, sex, age, marital status, education level, and employment status, only marital status was statistically significantly associated with cigarette smoking. Cigarette use was more prevalent among married/married before/co-habiting respondents compared to respondents who were single, $16.8 \%$ versus $9.4 \%$. On the current use of shisha, only the sex of respondents was of significant importance. Compared to females, shisha use was more prevalent among males, $13.6 \%$ versus $3.2 \%$ (Table 2). 
Table 2. Distribution of current cigarette and shisha smokers by demographic characteristics

\begin{tabular}{|c|c|c|c|c|c|c|}
\hline \multirow[t]{3}{*}{ Characteristics } & \multicolumn{3}{|c|}{ Current cigarette smoking } & \multicolumn{3}{|c|}{ Current shisha smoking } \\
\hline & $\begin{array}{c}\text { Smokers } \\
(n=51)\end{array}$ & $\begin{array}{c}\text { Non- } \\
\text { smokers } \\
(n=338)\end{array}$ & & $\begin{array}{c}\text { Smokers } \\
(n=40)\end{array}$ & $\begin{array}{c}\text { Non- } \\
\text { smokers } \\
(n=349)\end{array}$ & \\
\hline & n (row \%) & n (row \%) & $\mathbf{p}$ & n (row \%) & n (row \%) & $\mathbf{p}$ \\
\hline \multicolumn{7}{|l|}{ Residence } \\
\hline Urban & $17(12.6)$ & $118(87.4)$ & 0.825 & $14(10.4)$ & $121(89.6)$ & 0.967 \\
\hline Urban slum & $34(13.4)$ & $220(86.6)$ & & $26(10.2)$ & $228(89.8)$ & \\
\hline \multicolumn{7}{|l|}{ Sex } \\
\hline Male & $33(12.5)$ & $232(87.5)$ & 0.574 & $36(13.6)$ & $229(86.4)$ & 0.001 \\
\hline Female & $18(14.5)$ & $106(85.5)$ & & $4(3.2)$ & $120(96.8)$ & \\
\hline \multicolumn{7}{|l|}{ Age (years) } \\
\hline $18-25$ & $10(8.2)$ & $112(91.8)$ & 0.147 & $12(9.8)$ & $110(90.2)$ & 0.257 \\
\hline $26-35$ & 16 (12.9) & $108(87.1)$ & & $18(14.5)$ & $106(85.5)$ & \\
\hline $36-45$ & $11(15.7)$ & $59(84.3)$ & & $4(5.7)$ & $66(94.3)$ & \\
\hline $46-70$ & $14(19.2)$ & $59(80.8)$ & & $6(8.2)$ & $67(91.8)$ & \\
\hline \multicolumn{7}{|l|}{ Marital status } \\
\hline Married/married before/co-habiting & $33(16.8)$ & $164(83.2)$ & 0.031 & $15(7.6)$ & $182(92.4)$ & 0.079 \\
\hline Single & $18(9.4)$ & $174(90.6)$ & & 25 (13.0) & $167(87.0)$ & \\
\hline \multicolumn{7}{|l|}{ Education level* } \\
\hline No, primary, JHS, middle & $30(16.7)$ & $150(83.3)$ & 0.137 & $21(11.7)$ & $159(88.3)$ & 0.582 \\
\hline Senior high school/vocational & $14(9.5)$ & $134(90.5)$ & & $12(8.1)$ & $136(91.9)$ & \\
\hline Tertiary & $6(10.9)$ & $49(89.1)$ & & $5(9.1)$ & $50(90.9)$ & \\
\hline \multicolumn{7}{|l|}{ Employment status } \\
\hline Yes & $38(12.1)$ & $277(87.9)$ & 0.207 & $29(9.2)$ & $286(90.8)$ & 0.149 \\
\hline No & $13(17.6)$ & 61 (82.4) & & 11 (14.9) & $63(85.1)$ & \\
\hline
\end{tabular}

*Six respondents had missing data. JHS: junior high school.

Association between demographic characteristics and cigarette and/or shisha smoking

Seventy-six respondents (19.5\%; 95\% Cl: 15.9-23.8) were current smokers of either cigarettes or shisha. The results of the association between the demographic characteristics of the respondents and cigarette/shisha use are presented in Table 3. Sex, age, education level, and employment status, were included in the multivariate logistic regression analysis.

Table 3. Association between demographic characteristics and cigarette/shisha smoking

\begin{tabular}{|c|c|c|c|c|c|c|}
\hline Characteristics & $\begin{array}{c}\text { Smokers } \\
(n=76) \\
n(\%)\end{array}$ & $\begin{array}{c}\text { Non- } \\
\text { smokers } \\
(n=313) \\
n(\%)\end{array}$ & OR $(95 \% \mathrm{CI})$ & $\mathbf{p}$ & AOR $(95 \% \mathrm{CI})$ & $\mathbf{p}$ \\
\hline \multicolumn{7}{|l|}{ Residence } \\
\hline Urban & 25 (18.5) & $110(81.5)$ & 1 & 0.711 & & \\
\hline Urban slum & $51(20.1)$ & 203 (79.9) & $1.11(0.78-1.57)$ & & & \\
\hline \multicolumn{7}{|l|}{ Sex } \\
\hline Male & $55(20.8)$ & $210(79.2)$ & 1 & 0.371 & 1 & 0.565 \\
\hline Female & 21 (16.9) & $103(83.1)$ & $0.78(0.54-1.12)$ & & $0.84(0.47-1.51)$ & \\
\hline
\end{tabular}


Table 3. Continued

\begin{tabular}{|c|c|c|c|c|c|c|}
\hline Characteristics & $\begin{array}{c}\text { Smokers } \\
\begin{array}{c}(n=76) \\
n(\%)\end{array}\end{array}$ & $\begin{array}{c}\text { Non- } \\
\text { smokers } \\
(n=313) \\
n(\%)\end{array}$ & OR (95\% CI) & $\mathbf{p}$ & AOR $(95 \% \mathrm{CI})$ & $\mathbf{p}$ \\
\hline \multicolumn{7}{|l|}{ Age (years) } \\
\hline $18-25$ & $18(14.8)$ & $104(85.2)$ & 1 & 0.345 & 1 & 0.198 \\
\hline $26-35$ & $29(23.4)$ & $95(76.6)$ & $1.76(1.15-2.70)$ & & $2.20(1.07-4.52)$ & \\
\hline $36-45$ & $13(18.6)$ & $57(81.4)$ & $1.32(0.79-2.20)$ & & $1.78(0.75-4.23)$ & \\
\hline $46-70$ & $16(21.9)$ & $57(78.1)$ & $1.62(1.00-2.64)$ & & $1.69(0.72-3.96)$ & \\
\hline \multicolumn{7}{|l|}{ Marital status } \\
\hline Married/married before/co-habiting & $39(19.8)$ & $158(80.2)$ & 1 & 0.896 & & \\
\hline Single & $37(19.3)$ & $155(80.7)$ & $0.97(0.70-1.34)$ & & & \\
\hline \multicolumn{7}{|l|}{ Education level* } \\
\hline No, primary, JHS, middle & $41(22.8)$ & $139(77.2)$ & 1 & 0.186 & 1 & 0.251 \\
\hline Senior high school/vocational & $22(14.9)$ & $126(85.1)$ & $0.59(0.41-0.86)$ & & $0.60(0.32-1.11)$ & \\
\hline Tertiary & $10(18.2)$ & $45(81.8)$ & $0.75(0.46-1.25)$ & & $0.73(0.33-1.61)$ & \\
\hline \multicolumn{7}{|l|}{ Employment status } \\
\hline Yes & $55(17.5)$ & $260(82.5)$ & 1 & 0.040 & 1 & 0.013 \\
\hline No & $21(28.4)$ & $53(71.6)$ & $1.87(1.28-2.74)$ & & $2.30(1.19-4.44)$ & \\
\hline
\end{tabular}

*Six respondents had missing data. OR: odds ratio. AOR: adjusted odds ratio. Cl: confidence interval. JHS: junior high school.

In the multivariate analysis, only employment status was significantly associated with cigarette or shisha use. The odds of cigarette/shisha use for respondents who had no employment were 2.3 times the odds for those who had employment (OR=2.30; 95\% Cl: 1.19-4.44, $\mathrm{p}=0.013)$.

\section{DISCUSSION}

We sought to assess the predictors of tobacco use (cigarettes/shisha) among two communities in two districts in Accra, to provide data that will support intervention and prevention policies in Ghana. Our findings show that current cigarette use was 13.1\% (95\% Cl: 10.1-16.9), current shisha use $10.3 \%$ (95\% Cl: 7.6-13.7) and 19.5\% (95\% Cl: 15.9-23.8) smoked either cigarettes or shisha. The cigarette smoking prevalences in the two communities are a little above the national prevalence of $10 \%$ among adults aged 15-49 years $^{21}$. There are no nationally representative data on shisha however, the studies conducted reported varying prevalences ${ }^{22-24}$ including the youth prevalence of $1.3 \%{ }^{9}$. Studies on waterpipe use or shisha in the African region are few. Our findings on shisha use differ from those of a related study in a poor urban community in Johannesburg which reported $60 \%$ of high school students ever used, while $20 \%$ were daily users ${ }^{25}$. Similar studies conducted in Nigeria and Rwanda (Kigali) reported a shisha prevalence of $7.1 \%{ }^{26}$ and $20.8 \%^{27}$, respectively.

The reasons for the use of shisha were not different from other findings where participants believed shisha is a safer alternative to cigarette smoking, and used it out of curiosity and peer influence $23,24,26,27$. Shisha smoking has emerged in Ghana and gradually has become a public health issue that needs immediate response from policy providers and must be effectively regulated like any other tobacco product.

In the multivariate analysis, only unemployment was found to be significantly associated with higher odds of smoking cigarettes and/or shisha. Other studies ${ }^{28,29}$ have reported similar results. In a study conducted in Sri Lanka ${ }^{30}$, employment and monthly income were found to be associated with tobacco use. Similarly, in a Korean study, unemployment was found to be a significant risk factor for failure to quit and smoking relapse ${ }^{31}$, which agrees with our findings. Since unemployment is a significant risk factor for failure to quit, it is suggested that those with no employment smoke more and are less likely to quit. A related study in Ghana suggests that public policies for the promotion of higher educational achievement and improvement in income are important in smoking reduction and cessation ${ }^{32}$. Substance abuse can be challenging for several reasons including dependence on toxic substances, which usually affect health and also employment status ${ }^{33}$. Despite this, the cross-sectional evidence is only associative and does not address the issue of causality, hence further studies are recommended, especially longitudinal. In a similar study by Abdel-Hady and El-Gilany ${ }^{34}$ in Egypt, an association between 
tobacco use and education and also sex was found, which is not consistent with our findings. According to them, lower education level is a significant independent predictor for current smoking in older people, which is also consistent with other studies ${ }^{35,36}$. Also in the United States, adults with lower levels of education, who also are unemployed, or live near or below the US Federal poverty level are considered to have low socioeconomic status (SES) and turn to smoking cigarettes more ${ }^{37}$. Our study could not establish these associations except that of employment, hence the need for further studies.

Our study suggests attention should be given to social inequality in smoking since unemployment could predict smoking uptake and decrease quitting. When this happens, it can derail government efforts in curbing tobacco prevalence in the country. Also, it is suggested that attention is given to specific populations, especially the unemployed, for targeted education on the harmful effects of tobacco use. This can be done alongside the implementation of comprehensive smoke-free laws and other strategies, which are proven to reduce smoking prevalence and adverse health outcomes ${ }^{38,39}$.

\section{Strengths and limitations}

The study had some limitations which include the sample size which was only limited to two districts that are not representative of the nation and not generalizable. Also, since this was a cross-sectional survey that relies on selfreports, there is the possibility that socially desirable responses were given and that there might have been recall bias. Nevertheless, it is expected that the findings will form the basis for further nationally representative studies. As the data were cross-sectional, we cannot make firm conclusions regarding the causal pathway connecting unemployment and smoking.

\section{CONCLUSIONS}

When smoke-free laws and key policies are implemented, attention to social inequality in smoking must be considered to avoid derailing government efforts in tobacco control. Also, policy formulation to prevent smoking uptake must take into account specific populations to have maximum effect, especially people who are not employed.

\section{ACKNOWLEDGEMENTS}

The authors thank all the staff of Vision for Alternative Development for their support during fieldwork for this study, and the staff of The Research and Development Division of the Ghana Health Service, especially Adams Sheriffdeen for support in managing the data. We also acknowledge the District Officers in the study sites for their support.

\section{CONFLICTS OF INTEREST}

The authors have completed and submitted the ICMJE Form for Disclosure of Potential Conflicts of Interest and none was reported.

\section{FUNDING}

There was no source of funding for this research.

\section{ETHICAL APPROVAL AND INFORMED CONSENT}

Ethical approval for the study was obtained from the Ghana Health Service Ethics Review Committee (GHSERC017/08/17). Also, permission was sought from the Municipal Assembly before the conduct of the study. Informed consent was obtained from all participants.

\section{DATA AVAILABILITY}

The data supporting this research are available from the authors on reasonable request.

\section{AUTHORS' CONTRIBUTIONS}

LMM, DDL and FBO conceived the idea and conceptualized the study. FBO conducted the data analysis, and LMM and DDL wrote the first draft. SAA, ZN, LB and JKB contributed significantly to the statistical analyses. LB and JKB provided critical contributions to the discussion of the findings of the study. All authors contributed to the study design and review of the manuscript.

\section{PROVENANCE AND PEER REVIEW}

Not commissioned; externally peer reviewed.

\section{REFERENCES}

1. World Health Organization. The WHO Framework Convention on Tobacco Control: an overview. January 2015. Accessed October 6, 2021. https://www.who.int/fctc/about/WHO_ FCTC_summary_January2015.pdf?ua=1

2. World Health Organization. Tobacco fact sheet. Updated July 26, 2021. Accessed August 30, 2020. https://www.who.int/ en/news-room/fact-sheets/detail/tobacco

3. Amlung M, Vedelago L, Acker J, Balodis I, MacKillop J. Steep delay discounting and addictive behavior: a meta-analysis of continuous associations. Addiction. 2017;112(1):51-62. doi:10.1111/add.13535

4. Do YK, Bautista MA. Tobacco use and household expenditures on food, education, and healthcare in low- and middleincome countries: a multilevel analysis. BMC Public Health. 2015;15(1):1098. doi:10.1186/s12889-015-2423-9

5. John RM, Mamudu HM, Liber AC. Socioeconomic implications of tobacco use in Ghana. Nicotine Tob Res. 2012;14(10):1205-1212. doi:10.1093/ntr/nts013

6. St Claire S, Fayokun R, Commar A, Schotte K, Prasad VM. The World Health Organization's World No Tobacco Day 2020 Campaign Exposes Tobacco and Related Industry Tactics to Manipulate Children and Young People and Hook a New Generation of Users. J Adolesc Health. 2020;67(3):334-337. doi:10.1016/j.jadohealth.2020.06.026

7. O'Connor RJ. Non-cigarette tobacco products: what have we learnt and where are we headed? Tob Control. 2012;21(2):181190. doi:10.1136/tobaccocontrol-2011-050281 
8. Salloum RG, Lee J, Mostafa A, et al. Waterpipe Tobacco Smoking among University Students in Three Eastern Mediterranean Countries: Patterns, Place, and Price. Subst Use Misuse. 2019;54(14):2275-2283. doi:10.1080/10826084.2019.1645177

9. Logo DD, Kyei-Faried S, Oppong FB, et al. Waterpipe use among the youth in Ghana: Lessons from the Global Youth Tobacco Survey (GYTS) 2017. Tob Induc Dis. 2020;18(May):1-11. doi:10.18332/tid/120937.

10. van der Merwe N, Banoobhai T, Gqweta A, et al. Hookah pipe smoking among health sciences students. S Afr Med J. 2013;103(11):847-849. doi:10.7196/samj.7448

11. Minaker LM, Shuh A, Burkhalter RJ, Manske SR. Hookah use prevalence, predictors, and perceptions among Canadian youth: findings from the 2012/2013 Youth Smoking Survey. Cancer Causes Control. 2015;26(6):831-838. doi:10.1007/s10552-015-0556-x

12. Maziak W, Jawad M, Jawad S, Ward KD, Eissenberg T, Asfar T. Interventions for waterpipe smoking cessation. Cochrane Database Syst Rev. 2015;2015(7):CD005549. doi:10.1002/14651858.CD005549.pub3

13. Muzammil, Al Asmari DS, Al Rethaiaa AS, et al. Prevalence and Perception of Shisha Smoking among University Students: A Cross-sectional Study. J Int Soc Prev Community Dent. 2019;9(3):275-281. doi:10.4103/jispcd.JISPCD_407_18

14. Ekpu VU, Brown AK. The Economic Impact of Smoking and of Reducing Smoking Prevalence: Review of Evidence. Tob Use Insights. 2015;8:1-35. doi:10.4137/TUI.S15628

15. Owusu-Dabo E, Lewis S, McNeill A, Gilmore A, Britton J. Support for smoke-free policy, and awareness of tobacco health effects and use of smoking cessation therapy in a developing country. BMC Public Health. 2011;11(1):572. doi:10.1186/1471-2458-11-572

16. American Cancer Society. The Tobacco Atlas: Ghana. Accessed October 6, 2021. https://tobaccoatlas.org/ country/ghana/

17. Ministry of Health, Ghana Health Service, World Health Organization, Centers for Disease Control and Prevention. Global Youth Tobacco Survey 2017: Fact Sheet, Ghana 2017. Updated November 29, 2018. Accessed September 11, 2020. https://nccd.cdc.gov/GTSSDataSurveyResources/ Ancillary/DownloadAttachment.aspx?ID=3476

18. Owusu G, Agyei-Mensah S, Lund R. Slums of hope and slums of despair: Mobility and livelihoods in Nima, Accra. Nor Geogr Tidsskr - Nor J Geogr. 2008;62(3):180-190. doi:10.1080/00291950802335798

19. Ghana Statistical Service. 2010 Population and Housing Census Final Results. May 31, 2012. Accessed October 6, 2021. https://catalog.ihsn.org//catalog/3780/ download/52416

20. Global Adult Tobacco Survey Collaborative Group. Global Adult Tobacco Survey (GATS): Core Questionnaire with Optional Questions, Version 2.1. Centers for Disease Control and Prevention; 2014. Accessed October 6, 2021. https://www.
paho.org/hq/dmdocuments/2017/6-GATS-CoreQuestionn airewithOptionalQuestions-13June2014.pdf

21. Ghana Statistical Service (GSS), Ghana Health Service (GHS), and ICF International. Ghana Demographic and Health Survey 2014. Ghana Statistical Service (GSS), Ghana Health Service (GHS), and ICF International; 2015. Accessed October 6, 2021. https://dhsprogram.com/pubs/pdf/FR307/FR307. pdf

22. Parimah F, Davour MJ, Tetteh C, Okyere-Twum E. Shisha Use Is Associated with Deviance among High School Students in Accra, Ghana. J Psychoactive Drugs. 2021;1-7. doi:10.1080/02791072.2021.1907002

23. CSOs call on government to ban shisha smoking in Ghana. Ghana Business News. June 3, 2020. Accessed October 4, 2021. https://www.ghanabusinessnews.com/2020/06/03/ csos-call-on-government-to-ban-shisha-smoking-inghana/

24. Shisha is illegal in Ghana - FDA. GhanaWeb. April 18, 2019. Accessed October 4, 2021.https://www.ghanaweb.com/ GhanaHomePage/NewsArchive/Shisha-is-illegal-in-GhanaFDA-739656

25. Senkubuge F, Ayo-Yusuf OA, Louwagie GM, Okuyemi KS. Water pipe and smokeless tobacco use among medical students in South Africa. Nicotine Tob Res. 2012;14(6):755760. doi:10.1093/ntr/ntr211

26. Lasebikan VO, Ola BA, Lasebikan TO. Shisha smoking in selected nightclubs in Nigeria. Pan Afr Med J. 2019;33:136. doi:10.11604/pamj.2019.33.136.17149

27. Omotehinwa OJ, Japheths O, Damascene IJ, Habtu M. Shisha use among students in a private university in Kigali city, Rwanda: prevalence and associated factors. BMC Public Health. 2018;18(1):713. doi:10.1186/s12889-018-5596-1

28. Castaldelli-Maia JM, Masters N. The relationship between smoking and unemployment: New avenues for interdisciplinary research. Int J Soc Psychiatry. 2015;61(6):613-614. doi:10.1177/0020764015589603

29. Everding J, Marcus J. The effect of unemployment on the smoking behavior of couples. Health Econ. 2020;29(2):154170. doi:10.1002/hec.3961

30. Fernando HN, Wimaladasa ITP, Sathkoralage AN, et al. Socioeconomic factors associated with tobacco smoking among adult males in Sri Lanka. BMC Public Health. 2019;19(1):778. doi:10.1186/s12889-019-7147-9

31. Jung $Y$, Oh J, Huh S, Kawachi I. The effects of employment conditions on smoking status and smoking intensity: the analysis of Korean labor \& income panel 8(th)-10(th) wave. PLoS One. 2013;8(2):e57109. doi:10.1371/journal.pone.0057109

32. Nketiah-Amponsah E, Afful-Mensah G, Ampaw S. Determinants of cigarette smoking and smoking intensity among adult males in Ghana. BMC Public Health. 2018;18(1):941. doi:10.1186/s12889-018-5872-0

33. Unemployment \& Substance Abuse. Vertava Health Massachusetts. January 25, 2021. Accessed October 4, 2021. https://vertavahealthmassachusetts.com/blog/ 
unemployment-substance-abuse/

34. Abdel-Hady D, El-Gilany AH. Tobacco use and its associated factors among older people: A community-based study in Egypt. East Mediterr Heal J. 2020;26(1):68-74. doi:10.26719/2020.26.1.68

35. Gilman SE, Martin LT, Abrams DB, et al. Educational attainment and cigarette smoking: a causal association? Int J Epidemiol. 2008;37(3):615-624. doi:10.1093/ije/dym250

36. Tomioka K, Kurumatani N, Saeki K. The Association Between Education and Smoking Prevalence, Independent of Occupation: A Nationally Representative Survey in Japan. J Epidemiol. 2020;30(3):136-142. doi:10.2188/jea.JE20180195

37. Cigarette Smoking and Tobacco Use Among People of Low Socioeconomic Status. Centers for Disease Control and Prevention. Updated November 25, 2019. Accessed October 4, 2021. https://www.cdc.gov/tobacco/disparities/low-ses/ index.htm.

38. Hoffman SJ, Poirier MJP, Rogers Van Katwyk S, Baral P, Sritharan L. Impact of the WHO Framework Convention on Tobacco Control on global cigarette consumption: quasiexperimental evaluations using interrupted time series analysis and in-sample forecast event modelling. BMJ. 2019;365:l2287. doi:10.1136/bmj.l2287

39. Gravely S, Giovino GA, Craig L, et al. Implementation of key demand-reduction measures of the WHO Framework Convention on Tobacco Control and change in smoking prevalence in 126 countries: an association study. Lancet Public Health. 2017;2(4):e166-e174. doi:10.1016/S2468-2667(17)30045-2 